\title{
SOBRE LA FUNCIÓN Y EL OBJETO DE LOS SENTIDOS EN LA GNOSEOLOGÍA PLATÓNICA ${ }^{1}$
}

La presencia simultánea y cooperante de los factores eidético y empírico en el conocimiento humano ha sido siempre admitida, explícita o implícitamente, por toda reflexión gnoseológica, tal vez ya desde los primeros atisbos en Heráclito, Empédocles y Anaxágoras. Una negación absoluta de la presencia y acción de uno de los dos factores no parece poder demostrarse, ni del empírico en los más extremos idealistas — como tal vez lo sea Fichte-.., ni del eidético en los más radicales empiristas o sensualistas -como podrían ser Demócrito, Locke o Condillac. Por lo demás, la negación absoluta no parece derivar propiamente de la reflexión gnoseológica misma, sino más bien, por un lado, de tesis metafísicas extremas, que niegan por principio la existencia real y objetiva, sea de cualquier entidad considerada como espíritu, mente, razón, entendimiento, etc., sea de toda cosa reconocida como materia, cuerpo, animalidad, procesos bio-fisiológicos, etc.; o, por otro lado, de tesis moderadas, según las cuales se atribuye al cuerpo una inferioridad entitativa y se lo considera o como una cárcel en la que el alma se encuentra prisionera o como un impedimento para las operaciones del espiritu: tesis éstas, como precisamente la de Platón, que tienen en su origen una doctrina o un ideal moral de perfección humana.

Sin duda, de las tesis extremas que se mencionaron, la espiritualista ha sido sostenida mucho más raramente que la materialista, sobre todo en la radicalidad dicha y en conexión con la teoría del conocimiento. La materialista, en cambio, puede demostrarse en Demócrito y muchos de sus discípulos, así como en numerosos materialistas del siglo pasado y del presente. Pero esta dependencia de una tesis metafísica o de una doctrina moral no podría aducirse positiva y directamente en la argumentación, sino sólo en forma indirecta y negativa, en cuanto que no es una doctrina derivada de los principios, datos y fenómenos conocitivos, sino de tesis o presupuestos de otros campos.

En el campo estrictamente gnoseológico, lo dicho sobre la imposibilidad

1 Como obras de consulta para este ensayo he tenido a la vista las siguientes: Norman Gulley, Plato's Theory of Knowledge. Methuen \& Co. London, 1962; Francis Macdonald Cornford, Plato's Theory of Knowledge. Routledge \& Kegan Paul. London, 1964 (First ed. 1935). I. M. Crombie, An Examination of Plato's Doctrines. II. Plato on Knowledge and Reality. Routledge \& Kegan Paul, London, 1963. El texto griego de las citas traducidas fue tomado de Platonis Opera, Oxford Classical Texts. Oxford, 1967 . La traducción al español es personal mía. 
de demostrar la negación absoluta de uno u otro de los factores se basa no en las afirmaciones mismas de los filósofos, sino reductivamente en las implicaciones o derivaciones que pueden hacerse a partir de aquéllas. Expresado aquí de paso y en forma sumaria, esto quiere decir, con referencia a la negación del factor eidético, que toda gnoseología que pretende ser exclusivamente empírica recurre, y no puede menos de recurrir, a conceptos formales, estructuras y funciones, irreductibles a los fenómenos y procesos mismos de la sensibilidad y la experiencia, y necesitados de una facultad que los produzca. En efecto, aun prescindiendo de la generalización o universalización estricta, de la abstracción y de toda estructura o función puramente ideales (que ellos niegan), se impone de modo necesario la presencia de un acto y de una facultad diversa de toda sensación y experiencia que combine, agrupe, clasifique, distinga, defina, etc.; todo lo cual, por otra parte, es manifestado obviamente por el más rudimentario lenguaje y por el conocimiento más elemental, el del sentido común, si es que se llegara a negar el cientifico de las ciencias más positivas y empíricas.

La tarea formulada en el título de este ensayo es en realidad sólo una aplicación concreta del problema a un filósofo determinado, el más importante tal vez junto con Kant en el campo de la gnoseología. En efecto, el problema relativo a la función y alcance del factor empírico en el conocímiento ha :quedado, precisamente desde Platón, como un problema generạl y fundamental, sobre todo en las teorías idealistas, que pretenden o parecen negar la función real y validez de tal factor. El caso de Platón, como el de Kant - y Fichte-, es típico y decisivo para la aclaración y posible solución del problema a través de la historia del pensamiento, porque puede decirse que, resuelto el problema en su caso, que parece ser el extremo, quedaría resuel to para la filosofía misma.

Estas reflexiones sobre el factor empírico en el conocimiento tienen en el fondo el propósito de examinar el sentido y alcance del idealismo, para dẹmostrar dos puntos: ' $1^{\circ}$ que en él, en cuanto teoría del conocimiento, no está ni puede estar ausente de-modo absoluto el factor empírico, como base verdadera de conocimiento; y $2^{\circ}$, que el idealismo propiamente sólo destaca el factor intelectivo-ideal, precisando su función y efecto, sin negar o afirmar directamente — porque no puede ni le corresponde — nada sobre lo real (el mundo físico-sensible y el residuo entitativo), ni sobre la facultad que lo per̦cibe o se conecta con él.

Acerca del primer punto debe advertirse que directa y primáriamente se trata del conocimiento del mundo real - físico, empírico, sensible, "exterior", "independiente", etc.-, y no del conocimiento del mundo puramente 
ideal, como sería el de la lógica, la geometría y las matemáticas en general, pues de inmediato podría objetarse lo que tradicional y justamente se objeta sobre la no necesidad de apoyo o confirmación, y mucho menos fundamentación o derivación, en la experiencia, de las afirmaciones de tal conocimiento. Al decir esto, sin embargo, no se plantea el problema más profundo y radical sobre la no intervención absoluta en el conocimiento propio del ser humano, como acto total del mismo -.es decir, en su discurso, reflexión, meditación, indagación, juicio, estimación, etc., así como en y a través de los medios objetivos y subjetivos de estas operaciones - de los factores empíricos, sea directos, como la sensación y percepción, sea derivados, como la imaginación, la fantasía creadora, la memoria, etc. Afirmar la no intervención absoluta resultaría un absurdo imposible de sostener, porque este ser humano posee de facto y pone en acción al conocer, automáticamente, dentro y aun fuera de la conciencia, sus medios conocitivos sensibles "externos" e "internos", del mismo modo como también, en forma automática, dentro del acto total, pone en acción sus medios de conocimiento intelectivos. Con otras palabras, en sentido absoluto no existe y no puede darse ni un conocer puramente intelectivo-ideal, ni un conocer exclusivamente sensitivo-empirico: lo cual debe entenderse dicho, tanto en el caso de admitir una distinción irreductible entre ambos factores, como en el de aceptar una distinción sólo relativa (dentro de teorías metafísicas materialistas o espiritualistas radicales), pues en todo caso, absolutamente hablando, sería un acto total, indivisible, aunque formal y relativamente distinguible.

Acerca del segundo punto debe atenderse, primeramente, a no confundir el idealismo con un anti-realismo, por más que se puedan contraponer, a veces aun tan radicalmente, el idealismo y el realismo. Ambos términos y conceptos son o pueden ser equívocos. Porque pueden significar, de un lado, posiciones extremas, contrarias y excluyentes; de otro, el mero destacamiento o énfasis de un aspecto, elemento o factor. A mi juicio, sólo este uso y significado - que se halla manifiesto en Kant y Fichte, y podría verse también en Hartmann - es correcto, aunque tal vez sería mejor hablar de idealidad y realidad en el conocimiento; el primer sentido, en cambio, sólo se justificaría en cuanto se demostrara la presencia y acción exclusivas de uno u otro de los factores. En cuanto al aspecto de anti-realismo que sostienen en general los idealistas, debe decirse que se funda, o más bien se justifica, en una reacción frente al simple énfasis realista o ante la afirmación extrema de un realismo ontológico o trascendental, es decir, el que sostiene la independiente existencia en si de las determinaciones gnoseológico-ontológicas y que identifica absolutamente gnoseología y ontología, olvidando o ignorando lo propiamente intelectivo-ideal y lo exclusivamente empirico-entitativo.

Frente a las concepciones o más bien simples visiones directas e ingenuas, de primera intención y no de reflexión profunda, del fenómeno conocitivo, 
que sostiene el realismo ontológico, los llamados idealistas, desde Parménides, trataron de mostrar, por una parte, el alcance y la acción limitados de los datos fenoménico-empíricos, de los que partía aquella visión, y por otra, el papel y valor de las estructuras y funciones de la mente, manifestadas por la reflexión de una actitud más-auténticamente filosófica. El idealismo legítimo -que lo es el platónico— no niega, estricta y absolutamente hablando, la presencia ni la acción de los factores empíricos, sino que únicamente rechaza la atribución a éstos de la función y los efectos de los factores eidéticos, sea de una manera total, sea como origen y fundamento. Esta concepción parte de la evidente incapacidad de los factores empíricos para fundamentar el verdadero saber, lo más elevado y seguro del conocimiento humano, y encuentra en la mente o razón, guiado tal vez por las matemáticas, el único fundamento sólido e inmutable. El idealista empezó a ver la necesidad de la inversión copernicana, porque las cosas y sus datos inmediatos carecían de la claridad, precisión, inmutabilidad, seguridad, perfección, etc. que manifestaba la mente con sus conceptos y estructuras. Toda la reflexión del idealismo se ha encaminado a rechazar la conversión de lo empírico en eidético y la transformación de las "esencias" en ideas mediante abstracción desde las cosas. El idealismo no puede admitir que la compleja, fecunda y admirable operación de la mente sea reducida en su aspecto fundamental a la abstracción y recepción pasiva de imágenes y formas, así como al simple manejo combinatorio de elementos derivados del exterior.

Con respecto a los factores empíricos debe precisarse que los idealistas, con Parménides y Platón a la cabeza, ciertamente han negado en forma expresa, si no su presencia, sí su aportación válida y efectiva al conocimiento, y no precisamente al de la geometría y las matemáticas, sino al mismo del mundo físico sensible. Esto, sin embargo, es lo fundamental que debe precisarse. ¿Por qué la segunda vía de Parménides es la vía del error? Porque es la de la simple opinión del sentido común, de la mayoría, fundada en la sensación y la experiencia, las cuales, por sí mismas, pueden fácilmente inducir a error y cuyos datos no poseen firmeza, inmutabilidad, seguridad, etc. Pero, cimplica esto el rechazo total de los factores empíricos y de sus datos, la negación absoluta de la existencia de un mundo físico con características y determinaciones fundamentalmente diferenciables?

La respuesta posible de que esto es pura apariencia y no realidad, exige una precisión de términos. El mundo físico, captado, percibido y "conocido" por los medios empíricos, es sin duda sólo apariencia, fenómeno, aparecer; ellos sólo perciben lo que aparece y lo que perciben es sólo lo apareciente; y lo que aparece, lo fenoménico, posee estrictamente las características limitadas, relativas y hasta negativas que se le atribuyen, porque ello es así, o porque existe precisamente una correspondencia identificadora entre los factores conocitivos empíricos y los colores, sonidos, olores, etc.; es decir: existen 
en el ámbito humano ciertas realidades que tienen esas características y no otras y que son percibidas por esos instrumentos y no por otros. Aqui ocurre preguntar: lo aparente, o mejor apareciente, cno es real, no es una realidad, es decir, algo existente, que está ahí, aun cuando sólo sea devenir fluctuante, cambiante, evanescente, sin sostén firme e inmutable?

Ahora bien, el concepto o la categoria de realidad al que se contrapone apariencia, tanto en Parménides como en Platón, es sin lugar a dudas otro. Lo verdaderamente real, la auténtica realidad para ellos es el ser, lo uno, y cuanto a partir de ello es conocido o deducido por el nous, por la mente o razón. Lo en verdad real y existente es lo que existe por la idea y por el nous. Como todo lo sensible y empírico no puede ser conocido por éstos, ni deducido o establecido, entonces no es real, no existe realmente. La verdadera realidad depende de las características de la idea y del nous: evidencia, claridad, permanencia, inmutabilidad, perfección, eternidad, etc. Realidad y existencia perfecta y completa son una y la misma cosa. Según ello, lo empirico y sensible es irreal, porque no puede ni siquiera participar de aquellas cualidades. De ahí que debe establecerse la paridad eidético-real, como también la opuesta empirico-irreal=aparente.

Este concepto de realidad se contrapone diametralmente al sostenido por la filosofía trascendental y también al afirmado por el realismo (ontológico), si bien este último lo aplica aun a "esencias" y "formas" (que como tales, serían algo intelectivo-ideal), en cuanto que supone que existen singular e individualmente. Real aquí significa aquello que es "tocado", aquello con lo que se establece contacto precisamente por medio de los sentidos y la experiencia, ya que se considera a la función intelectivo-ideal como constitutiva y determinativa de la realidad, pero no como su aportadora o productora (en lo estrictamente entitativo). Real no sería propiamente un concepto con un contenido determinado, sino una referencia o un señalamiento inmediato, intuitivo, del mero hecho de existir, de estar ahí en la existencia y el mundo, independientemente - pero sin negarlas - de cualesquiera determinaciones intelectivo-ideales de ese "algo" o esa "materia" existente (=residuo último entitativo).

La doctrina platónica sostiene e implica una identificación entre idealidad y realidad, porque idea no es concepto ni abstracción, sino arquetipo presente de modo inmediato en el alma, ora visto antes en el tópos ouránios, ora recordado en este mundo: de ahí la calificación de su doctrina como idealismo ontológico o realismo de las ideas. En Platón la verdadera realidad es conocida y, según ello, se tendrá verdadero conocimiento, sólo cuando las ideas sean contempladas inmediatamente, es decir, en una vida del alma - -y del hombre - anterior y posterior, asi como diversa de ésta. De ahí que en la vida actual no puede haber conocimiento en sentido pleno, sino sólo aproximaciones a él, según se acerque nuestra alma a aquella contempla- 
ción. ${ }^{2}$ ¿Qué es, entonces, para Platón el tomar contacto empírico con el mundo físico circundante? Según veremos después en detalle, directamente significa sólo eso: sentir, percibir, captar, tocar, lo que aparece a los sentidos como algo cambiante y evanescente, como sombras o imágenes oscuras de la realidad verdadera, determinada y constituida; pero ello, sea lo que fuere, tiene que existir, estar ahi, pues no es ni se reduce a la nada.

Ahora bien, si hacemos una correspondencia adecuada y legítima entre las terminologías, podremos descubrir sin gran dificultad los siguientes puntos:

1) Que la aplicación del término ideal a entidades arquetípicas puras, del todo aempíricas, existentes y subsistentes por sí mismas -en cierta forma, actos puros, para emplear el lenguaje de Aristóteles, aunque no absolutos y primeros, excepto la Idea del Bien_, es única y en cuanto tal, es decir, sin pretender desentrañar su tal vez verdadero sentido por debajo del alegórico, no se presenta en filósofo alguno.

2) Que el posible sentido del término ideal dado a estructurás noéticoideales o categorías de la mente, que sin duda se advierte en Platón como momento segundo y derivado del anterior, se corresponde con el sentido ideal-trascendental y con el de los conceptos-ideas del realismo aristotélicoescolástico.

3) Que el término platónico que equivaldría a real —éste es, como se sabe, de origen latino y deriva a su vez del vocablo res: cosa- (mejor sería

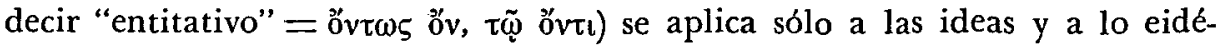
tico, pues ellas son lo único que verdadera y realmente es o existe.

4) Que lo entendido por la gnoseología moderna, sobre todo la trascendental -y aun ya antes por la escolástica-, como real, se deduce obvia y eficazmente del contexto platónico sobre la función y efectos de la sensibilidad misma, que en su posición natural no puede tener como correlato lo no-existente en absoluto, sino en todo caso un relativo ente y un relativo no-ente, viniendo a ser ésta, en Platón, una acepción segunda, referida no a lo que es plena, perfecta y definitivamente, sino a lo que siempre deviene, a lo que en cierta forma "es" deveniente, a lo que siempre permanece imperfecto - como la esencia del movimiento según Aristóteles-, pero que de alguna manera es o existe "realmente", aun como un aparecer, y que no se reduce a una ficción de la fantasía o a una deformación congénita de la sensibilidad humana - deformación que implicaría un error naturae o una naturaleza enferma (el que Platón considere al hombre en su estado actual como un ser caído, prisionero, esclavo, no implica nada de lo anterior, pues para él las operaciones de los sentidos son normales y correctas; Platón nunca subestimó o descalificó los datos empíricos porque procedieran de órganos, funciones o

2 Cfr. Fedón $66 \mathrm{e}-67 \mathrm{~b}$. 
facultades deformadas por naturaleza, ${ }^{3}$ sino que lo único negativo atribuido a ellos es su incapacidad para elevarse hasta las ideas, para conocer en sentido estricto lo que real y verdaderamente es; y, a su vez, lo únicó negativo en el hombre es la condición misma del alma prisionera en la cárcel del cuerpo).

\section{II}

Al examinar las afirmaciones platónicas sobre el conocimiento sensible, o más bien sobre la sensación, es necesario tomar en cuenta, más que lo dicho por Platón mismo, lo implicado en sus asertos, porque es muy posible y parece evidente que en virtud de sus propósitos directos Platón sostiene la no aportación de los sentidos al conocimiento, sin atender de modo consciente a que sus mismas afirmaciones llevan consigo en muchos aspectos el aceptar tal aportación. Demostrar esto no me parece en realidad una tarea difícil.4 La que sí lo es, sin duda, es la precisión del término y concepto conocimiento, o de su distinción en clases o niveles; lo es también la aclaración de aquello en que consiste o debe consistir dicha aportación, y la función y el alcance de la sensibilidad, así como de su objeto.

A mi juicio hay un primer punto claro. Explícita y técnica o especifica-

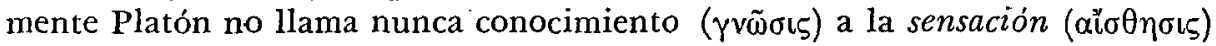
ni la considera jamás como tal. ${ }^{5}$ Aunque deductivamente se pueda hablar de la presencia de un conocimiento sensible en Platón, él nunca se servirá de este término, tal vez precisamente porque no distingue en forma expresa y directa dos clases, especies o niveles de conocimiento. Lo más exacto que se puede decir es que para él hay conocimiento y hay sensación. En cierto sen-

3 Según mis conocimientos no hay en toda la obra platónica la más minima referencia a un estado anormal o degenerado de la sensación, proveniente de la naturaleza humana, concebida como alma condenada a habitar en la cárcel del cuerpo; ni alusión alguna a perturbaciones o deformaciones objetivas _es decir, de los datos, resultados u objetos proporcionados por los sentidos_, en virtud de influjos atribuibles a la constitución dicotómica del hombre, en la que la parte material se concibe como factor de imperfección, limitación, obstáculo y hasta degradación.

4 Con lo expresado no quiero decir que especificamente la aportación negada resulte incluida, sobre todo si se trata del conocimiento ideal y puramente teórico; sino, más bien, que la afirmación misma de la sensación, objetiva y válida en su propio dominio, implica una presencia y colaboración natural $y$ fundamental en el acto total de un ser no puramente animico o intelectivo sino humano e integral. ¿Cuánto debe, por ejemplo, todo cl lenguaje explicativo de los conocimientos ideales o teóricos a las percepciones sensibles? Cfr. lo dicho en la p. 17. Y lo que opino sobre la facilidad de la demostración, lo refiero al aspecto lógico, no al psicológico-gnoseológico, que sin duda requiere análisis profundisimos y amplísimos.

5 Esto es absolutamente seguro e indudable, en lo que se refiere a los planteamientos específicos estrictos, es decir, al sentido técnico del término. En otros casos sí lo usa, pero el contexto mismo indica un sentido general. Por ej., Fedón 73 c 6-8: "Si alguien, habiendo visto $\mathrm{u}$ oído algo, o habiéndolo percibido por algún otro sentido, no sólo conociera

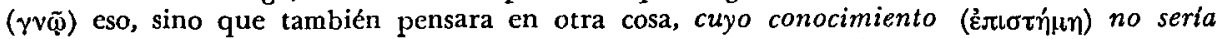
el mismo, sino otro..."; o d 7: Conocieron (z $\gamma v \omega \sigma \alpha v)$ la lira..." 
tido Platón no se planteó el problema de si la sensación es conocimiento, es decir, un tipo o una clase de conocer: porque la hipótesis que se examina en el Teeteto es si la sensación es el conocimiento; si la ciencia o el conocimiento es o se reduce a la sensación; si lo específico o constitutivo del conocer se' halla en la sensación.

Aunque para algunos resulte superfluo o sobreentendido, creo necesario recordar que la aplicación a las doctrinas platónicas de planteamientos de nuestro tiempo puede resultar inadecuada e infructuosa, como lo sería, por ejemplo, hablar de conocimiento sensible en su filosofía. Para Platón existe, por un lado, conocimiento - ciencia, saber, contemplación- $y$, por otro, sensación. En sentido platónico y dentro de tal enfoque, la sensación no sólo no es el conocimiento, sino que tampoco es conocimiento. Ni siquiera la opinión verdadera con razón -siguiendo el desarrollo del Teeteto- es reconocida como tal. ${ }^{6}$ Más aún, conocimiento y sensación se oponen radicalmente, tanto en sí mismas como facultades y operaciones, como en sus objetos: por eso precisamente se le niega a ésta el carácter de aquél.

Dentro de sus perspectivas, Platón no tiene que recurrir al aporte empirico para salvaguardar el único y verdadero realismo - como en la filosofía trascendental y en toda dirección realista-, pues para él la única realidad verdadera es la de las ideas y la derivada de ahí mediante la participación. Por ello la sensación tiene otro papel: el de servir de contacto con el mundo del devenir, esto es, de la apariencia y de lo irreal en sentido platónico. Que tiene ese papel, es aserto constante en el Teeteto y punto de partida precisamente para negarle la categoría de conocimiento. Pero, si asi no fuera, fácilmente podría demostrarse que la más mínima afirmación platónica sobre los datos sensibles, simplemente como ejemplo y aun para negar su "realidad", implicaria su presencia y la necesidad de un instrumento por cuyo medio el alma los percibiera, aun dentro de su apariencia e "irrealidad".

Ahora bien, ese percibir y captar, ese contacto con los objetos o datos sensibles, ¿es conocimiento? Para Platón, clara y enfáticamente, no, como para toda teoría que no distinga entre conocimiento inteligible y sensible, que no admita éste y que reserve el término conocimiento sólo para la elaboración, conformación y constitución operada por el entendimiento, por el nous, sea sin aportación alguna de lo sensible ni referencia a ello, sea teniéndolo presente como contenido o "materia", diríamos, de cualquier afirmación o juicio acerca del mundo físico ("esto es rojo", "esto es una piedra"). Según ello, conocimiento en Platón es la operación especifica y consciente del nous

6 Ninguna de las tres proposiciones, discutidas en el diálogo, para convertir de alguna manera la sensación en conocimiento, tienen éxito, a pesar de que la última y más cercana

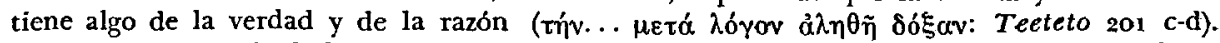
Pero la base principal de la negativa no es esto -que, por lo demás, no proviene de la sensación_, sino precisamente la inclusión de ésta como factor integrante y también es. pecífico $\rightarrow$ si no fuera esto último, bastaría el elemento o factor racional. 
que, contemplando las ideas o recordándolas, establece relaciones y formula asertos, sin necesidad o recurso ninguno a lo sensible en lo específico de tal operación. Todo esto se halla presente en las doctrinas platónicas; lo único que deductivamente se podría añadir, es lo dicho poco antes sobre la necesidad de lo sensible como contenido de las afirmaciones sobre el mundo físico.

Conocer es, entonces, específicamente algo diverso de sentir. Conocer es operación atribuida al entendimiento; sentir lo es, como a algo directo e inmediato, a los órganos sensoriales. Conocer es operación luminosa, clarificante, diáfana, exacta, nítida, incapaz de engaño, error o confusión, y sus objetos son conceptuables, definibles, perfectamente precisables, inmutables, eternos, permanentes. Sentir es operación oscura o imprecisa e inexacta, confusa y difusa, vaga e insegura, que conduce a error y engaño, cuyos objetos no pueden como tales conceptualizarse ni definirse; ellos son inasibles en su ser, porque más bien no hay tal ser, o porque su esencia consiste precisamente en el perpetuo devenir, flujo y cambio; son inconstantes, insubsistentes y a cada momento se desvanecen, existiendo una identidad, en cuanto a todas esas características, entre los instrumentos de la operación y los objetos o datos de la misma. Conocer es aplicar y manipular, en perfecta conciencia, conceptos y estructuras; sentir es, en su primer momento y origen, como dirá Kant, ser afectado, impresionado y presionado, hasta inconsciente y automáticamente, por vibraciones, tensiones, sacudidas, movimientos, roces, fricciones, radiaciones, etc. Aunque tal vez no con estas palabras y conceptos, pero sí con equivalentes y parecidos, Platón describe así en algunos desarrollos del Teeteto el fenómeno y los procesos de las operaciones de los sentidos. Considerado en su especificidad, conocimiento no es, pues, radical y absolutamente, sensación.

La posición platónica de reservar el término conocimiento ( $\gamma v \tilde{\omega} \sigma \iota \zeta)$ y

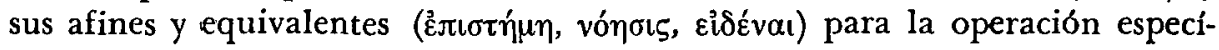
fica mencionada antes, es a mi juicio legitima, por cuanto hay suficientes bases para sostener su diversidad con respecto a la sensación, y es inobjetable en cuanto que no puede demostrarse ni, según sé, ninguna teoría ha pretendido demostrar, una identidad fundamental o una analogía esencial entre ambas operaciones. Entonces, y ya fuera de la perspectiva platónica, uno se pregunta: ¿es conocimiento la sensación? ¿Hasta qué grado ofrecen los sentidos una relación especificada y diferenciada con algo diverso del que siente? ¿Se puede y tiene sentido hablar de un conocimiento sensible? La respuesta negativa parecería ir contra toda la tradición y contra el consenso universal, y en cierto respecto aun contra la evidencia misma. Sin embargo, tal vez valdría la pena examinar si la expresión conocimiento sensible. no envuelve ya algo que no es la simple sensación o la mera percepción o más bien recepción sensorial, sin aportación ni trabajo alguno por parte del alma o de la facultad "conocitiva" en cuanto tal. Porque es indudable que Platón 
consideró como sensación la presencia de ciertos procesos y fenómenos unida esencialmente a la acción y disposición de los órganos de los sentidos, sin elaboración ninguna todavía de cualquier factor propiamente conocitivo. ${ }^{7}$ Esto podría también desprenderse justamente del doble sentido que parece atribuir Platón a la áisthesis, uno como simple sensación y otro como percepción aun acompañada de cierto factor judicativo. ${ }^{8}$

Si tal fuera el planteamiento platónico, debemos, a mi juicio, examinar si es o no el correcto; si en realidad puede llamarse a la pura sensación conocimiento sensible, al menos en un sentido analógico o por serlo en principio y embrionariamente; y si lo que nosotros denominamos hoy conocimiento sensible, incluye ya en cuanto tal algo diverso y añadido a aquélla. Para esclarecer las cosas podría argumentarse así: hay conocimiento, cuando entran en función factores especificos conocitivos; ahora bien, en la pura sensación no entran en función factores especificos conocitivos; luego la pura sensación no es conocimiento. La mayor parece evidente, por principio, pues resultaría contradictorio que hubiera conocimiento sin tales factores o que operando ellos no se diera aquél. La demostración de la menor implica fundamentalmente la posibilidad de la sensación pura; es decir, no que pueda darse en la realidad como algo aislado e independiente, como si fuera un estadio separado de hecho en un proceso, sino que pueda distinguirse con claridad por la mente, de manera que una cosa no sea la otra. Pues bien, tanto en las descripciones platónicas como en el análisis que puede llevarse a cabo, considero posible distinguir con cierta claridad los puros datos sensoriales, prescindiendo o abstrayendo de toda operación capaz de expresar o formular el conocimiento que se deriva de ellos, se les refiere o aplica, o los tiene como "materia" y contenido. En este sentido estricto, los animales, por ejemplo, no conocerían, sino sólo sentirían. ${ }^{9}$

¿Cuáles serían esos datos? A mi juicio, no los "fenómenos" o sucesos, subyacentes como "materia" - que ahora se conocen como vibraciones-y que constituyen la aportación del "objeto" para producir la sensación, sino los colores, sonidos, olores, etc., mismos, pero como detenidos en cuanto tales, es decir, como si el sujeto, teniendo abiertos y en acción todos sus órganos, se detuviera en eso sin formular ni expresar nada, sin aplicar su conciencia a lo percibido. Se trataría de una operación inconsciente e incompleta, porque, a pesar de estar realizada la sensación, el que percibe no ha

7 Por ej. véase Teeteto 153 d-154 a; $15^{6}$ a-157 a; 159 a-16o a; 182 a-d. Cfr. Gulley, o. c. en la nota $1, \mathrm{pp} .84,88,106$. Aparentemente, al explicar el proceso y la operación de los sentidos, Platón atribuiría a éstos el aportar ciertos datos, como por ej. distinciones y relaciones. Pero esto, aunque él no lo diga expresamente, no lo atribuye en realidad y cs sólo efecto del lenguaje explicativo.

8 Teeteto 179 c 2-4; cfr. Gulley, o. c., p. 48.

9 Platón atribuye expresamente la sensación a hombres y animales (cfr. la cita de la nota 59); pero en más de un pasaje pregunta irónicamente, si una bestia sería capaz de las operaciones propias del conocimiento. Por ejemplo, Teeteto 171 e 4.7 . 
hecho nada para reconocerla, comprobarla, aplicarla e incorporarla a la función integra del conocimiento consciente: no ha dicho ni siquiera "esto es rojo". ¿Cuál sería ese conocimiento? No puede ser otro que el del mundo físico, que por ser de éste incluiría dichos elementos y por ser tal comprendería los factores conocitivos.

La sensación pura -o tal vez mejor simplemente la sensación - estaría pues reducida y confinada a la región de la sensibilidad, en donde se llevan a cabo todos los fenómenos y procesos sensibles y las sensaciones en cuanto tales, pero sólo ellas: es el mundo de los colores, sonidos, olores, gustos, tactos, etc., diferenciados por los sentidos mismos, tanto en el seno de cada región, como respecto a las otras; pero, repetimos, sin que se dé la más minima expresión o formulación explicita de ninguna relación, porque esto ya no puede ser obra de la sensibilidad, sino de otro factor o potencia, capaz de producir esa formulación en virtud de su diversidad esencial y de su poder de reflexionar sobre las relaciones implícitas en ella y formulables. La sensación y su mundo serían como uno de los campos sobre el que trabajara o al que se aplicara el conocimiento, siendo, por cierto, ese trabajo y esa aplicación imperfectos e inferiores con relación a otros, por ejemplo, a las intuiciones puras de las matemáticas o a la contemplación misma de las ideas. Avanzando desde Platón podría aceptarse el término de conocimiento sensible, referido justamente a aquel que tuviera como trabajo y aplicación el mundo sensible -Platón llama opinión ( $\delta o ́ \xi \alpha)$ al tipo de "conocimiento" que tiene por objeto la generación ( esencia (ov̉oía), objeto de la inteligencia (vónoıs). ${ }^{10}$

\section{III}

No parece haber extrañado a nadie, en cuanto yo sé, que el fundador del llamado idealismo y tal vez su teórico más radical haya formulado una verdadera teoría de la sensación, más profunda tal vez, en los aspectos gnoseológicos, que la expuesta por Aristóteles, creador y máximo exponente del realismo. Si bien es cierto que el motivo principal del estudio de la sensibilidad es su refutación como conocimiento, sin embargo, en algunos desarrollos Platón se ocupa dẹl tema en una forma tan especial, que parece como si fuera una investigación directamente buscada y objeto de interés positivo para él. Sin duda, la teoría platónica de la sensación puede y requiere ser estudiada en muchos aspectos. En el presente ensayo yo voy a considerar sólo ciertos pasajes fundamentales desde el punto de vista estrictamente gnoseológico, y con el fin preciso de demostrar su validez, si no como conocimiento en un sentido específico y estricto - que podría ser el platónico-, sí como contacto y captación o percepción del mundo sensible, del ser como devenir,

10 República 534 a $2-3$. 
de la realidad como apariencia. Antes de examinar directamente algunos textos con el fin de seguir de cerca los momentos concretos de la reflexión platónica, trataré de establecer una demostración más bien teórica de la tesis, basada en los principios generales de la filosofía de Platón, manifiestos y conocidos de todos y que no ameritan una comprobación directa.

El punto de partida fundamental es sin duda el hecho, manifiesto y obvio, de que Platón maneja, emplea, analiza y describe todo el conjunto de lo que puede llamarse senșibilidad: actos, órganos, procesos, objetos, funciones, especificación —-cinco sentidos—, diversidad —externos e internos—, etc., de donde se desprende, en principio, que Platón no sólo no niega ni rechaza, sino que afirma y sostiene la presencia del factor empírico o instrumental sensible en el ser humano. La cuestión inmediata sería: ¿qué sentido tiene esa presencia o qué objeto y finalidad atribuye él a la sensación o puede deducirse que le atribuye? Puesta la condición o el medio subjetivo, que es la sensación misma, debemos suponer el correlato objetivo, pues por esencia y principio tiene que darse éste, ya que de otro modo carecería absolutamente de sentido o sería contradictorio poner el uno sin admitir o reconocer el otro. Si, pues, la sensación ha de tener un sentido y una finalidad, debe darse también un objeto de la misma. ¿Cuál es éste? El objeto es el mundo sensible, empirico o material, y la finalidad es poner en contacto con él al ser humano, existente en ese mundo y dotado con instrumentos para su existencia en él.

De lo anterior resulta incuestionable la presencia de la sensación y de su objeto. Ello no implica nada sobre el cómo ni sobre una determinada validez: es decir, la única validez y el solo alcance de la sensación es, repetimos, hacer presente al ser humano un mundo sensible. No se implica aquí en modo alguno que lo logrado a través de la sensación sea un producto suficiente y satisfactorio para él, porque no sólo no es un ser puramente sensible, sino que la sensibilidad es un dominio de contacto y relación ("conocimiento") con lo diverso de él, muy inferior en varios aspectos, tanto porque el otro medio, la inteligencia, constituye y precisa al mismo "conocimiento" sensible, como porque ese medio tiene dominios propios conocitivos, libres de la imperfección y defectos de la sensibilidad.

Cómo la sensación hace presente su objeto y qué calidad entitativa posee éste, es ya un aspecto secundario, que no invalida al anterior -es decir, la presencia misma aun aparente o apareciente del objeto (todo el mundo de la sensibilidad es, y sólo es, aparecer, manifestarse, producirse en la apariencia)-, pues de otra manera se caería en la contradicción y sinsentido señalados arriba, al poner un medio de relación o contacto sin objeto. Si la naturaleza del acto, el desarrollo del proceso, la forma de captación y el modo de ser del objeto son deficientes, imperfectos, impuros, inseguros, no fijos ni permanentes, etc., todo ello no puede negar su existencia o presencia 
misma, su estar ahi, como uno de los mundos o regiones para el ser humano. Este mundo puede ser lo que sea y como sea, pero está ahí, y parece imposible concebir al ser humano (no al alma pre- y postexistente) fuera de ese mundo.

Si el ser humano no es espiritu puro o alma sin cuerpo, es decir, si por esencia es un ser mixto, el mundo sensible es para él un medio necesario, así lo sea accidental y condicionalmente. El mundo sensible tiene que poseer una realidad del tipo que se quiera, pero ha de tenerla, a menos que se admita que en el aspecto sensible la vida del ser humano se lleva a cabo en un ámbito de pura ficción, de ensueño vago e ilusorio, de sombras verdaderas y no alegóricas. Porque sombra, imagen, apariencia (tal vez sería mejor decir aparición o manifestación) subjetivo-objetivas, según las doctrinas platónicas, no se reducen a fantasmagoría puramente subjetiva del alma. Aunque es cierto que en el aspecto sensible el ser humano, por su naturaleza misma, vive en un mundo imperfecto, inferior, inestable, impreciso, etc., sin embargo, ello no quiere decir que éste sea absolutamente irreal e inexistente.

Toda la "imaginería" platónica -metáforas, alegorías, comparaciones, ejemplos, etc.- es un ingrediente esencial en su pensamiento, al menos para hacerlo visible y comprensible, y por definición está constituida por el mundo sensible. Pero no sólo el mundo de imágenes platónico, sino sobre todo elementos fundamentales para su doctrina pertenecen al campo de lo sensible. Por ejemplo, la belleza física y la prestancia corporal, así como el amor mismo sensible y el placer erótico; la doctrina sobre las partes u órganos del cuerpo humano que corresponden a las funciones del alma o del ser humano; el papel que todo lo corporal desempeña en la constitución y diversificación del Estado, cuyos miembros son hombres, es decir, seres corpóreos y espirituales, que desarrollan sus actividades no sólo en el plano de la pura inteligencia, sino también en todos los planos de las necesidades físicas: alimentación, gimnasia y adiestramiento, ejercicios y actividades bélicas, etc.; todo lo referente a la música, como acordes y armonía, tensiones y proporciones, instrumentos y melodías, etc. ${ }^{11}$ ¿Puede acaso todo esto, y mucho más que pudiera decirse, ser afirmado y entendido sin atribuir, al menos implícita y tal vez forzadamente, una validez a la sensación y a su objeto? Yo lo considero imposible y absurdo: quien lo sostuviera, caería sin duda en un sinnúmero de contradicciones.

Otra base para la demostración de la tesis se puede tomar de lo implícito en la misma argumentación platónica contra la sensación como ciencia o conocimiento, desarrollada en el Teeteto. Pero vayan antes unas aclaraciones para reconocer la verdad y acierto de la doctrina de Platón. En primer

11 Cfr. República 530 d-531 e. Para la visión cfr. id. varios pasajes cortos y expresiones a lo largo de 529-532. 
lugar, hay que tomar en cuenta que toda la actitud platónica de rechazo de la sensación como conocimiento, debe entenderse en el sentido de rechazo radical y natural de la opinión ingenua del sentido común, basada en la mera percepción u observación sensible con pretensiones de ciencia. En segundo lugar, el meollo de la argumentación sobre por qué la sensación no es ciencia o conocimiento, es muy claro: la sensación no alcanza la verdad, porque no alcanza el ser; y si no alcanza a ambos, no es ciencia ni conocimiento. ¿Quién pretendería que la sensación alcanza el ser y la verdad, operación que tiene su sede en la afirmación judicativa del entendimiento? Además, es manifiesto que Platón, en forma directa, sólo tiende a demostrar que la sensación no es conocimiento en sentido estricto, pero no pretende negar o rechazar la sensación como sensación misma ni sus efectos u objetos; es decir, la sensación no es en verdad conocimiento, pero es sensación; o no por no ser conocimiento deja de ser sensación y de tener un sentido y un objeto.

Si el propósito directo de Platón debe considerarse no sólo como logrado, sino como cierto y verdadero, en cambio, el propósito indirecto o implícito -es decir, el de negar el sentido y el objeto de la sensación misma-, si es que lo hubiera, caería por su propio peso, al incluir positivamente en la refutación misma lo que negativamente pretende rechazar. Este punto de vista se demostraría como sigue: para refutar la tesis puesta en boca de Teeteto de que el conocimiento es la sensación, Platón estudia a fondo aquello en que consiste su esencia, los órganos adecuados, la disposición, el proceso, las condiciones o medios y, sobre todo, presenta los resultados de su pesquisa. Pues bien, la conclusión del largo discurso es negativa en cuanto a que la sensación sea el conocimiento; en lo fundamental, porque el objeto alcanzado por la sensación ofrece características radical y esencialmente diversas de las requeridas por la ciencia o por el verdadero conocimiento. Pero lo anterior encierra un resultado positivo, en cuanto que se asignó una función y un objeto a la sensación: el mundo sensible y empírico del devenir, así como el nexo con él del ser humano anímico. Si no fuera así, la refutación primera careceria de sentido, pues no habría fundamento ninguno para ella, si la sensación no tuviera papel ninguno ni objeto. Ciertas características de la sensación, de acuerdo con el desarrollo platónico, justifican aparentemente su asimilación a la ciencia; si esas características no existiesen, la equiparación no tendria base, resultando absurdo y ridículo asemejar la ciencia, aun en sus aspectos más elevados, con algo inoperante, sin función ni objeto.

Uno de los argumentos platónicos para demostrar la diferencia entre conocimiento y sensación parte de la presencia de algo común, de objetos o sensibles comunes - como fueron llamados - a diversos sentidos, distintos de los específicos y particulares de cada uno de ellos y que no pueden ser 
percibidos o conocidos por éstos. ${ }^{12}$ La reflexión platónica procede describiendo los sensibles propios, es decir, admitiéndolos y afirmándolos, señalándoles a cada uno de los cinco sentidos su objeto propio. Ahora bien, ¿sería posible distinguir con precisión radical unos objetos con respecto a otros, si no se tiene una noción clara de ellos y se supone la existencia de los unos como de los otros?

Otro fundamento para la demostración que vengo haciendo puede tomarse de la relación que, con algunas excepciones, establece casi siempre Platón entre las cosas individuales y concretas, percibidas por los sentidos, y las ideas conocidas y contempladas en una vida anterior. En efecto, si precisamente a esa percepción por los sentidos no se le atribuye una validez objetiva -así se refiera ésta a la simple entrega misma de las imágenes, aunque imperfecta y defectuosa-, carecería de todo valor la relación o comparación, porque o no existirian tales imágenes o no se explicaría suficientemente su origen, a menos que también se las supusiera provenientes de una vida anterior del alma.

IV

El acercamiento mismo al conjunto básico de los textos platónicos relativos al problema planteado aquí sobre el objeto y papel de la sensación (en particular ya nos referimos directamente a algunos), nos da la siguiente perspectiva, que expondremos en forma breve, aduciendo literalmente sólo las expresiones esenciales.

$1^{\circ}$ El aspecto negativo, esto es, el negar a los sentidos y a su operación capacidad específica para conocer en sentido estricto, aparece siempre en contraposición expresa a la capacidad y adecuación atribuidas a la ciencia y al conocimiento propiamente dicho - ejecutados por la razón, el pensamiento y la inteligencia-, para alcanzar el ser y la verdad. Los textos alusivos pueden considerarse dentro del esquema siguiente: 1) objeto por cono cer; 2) tipo de conocimiento y de facultad conocitiva; 3) incapacidad conocitiva de la sensación; 4) trasfondo ético-práctico del rechazo de lo sensible y corpóreo.

1) Objeto por conocer. Lo que Platón considera como objeto del conocimiento en sentido estricto no es propiamente algo uno e idéntico sino múltiple y diverso, aun cuando coincidan estos últimos en pertenecer al mundo inteligible y eidético. La diversidad puede situarse en estos campos: ontología, gnoseología, axiología, matemáticas, física, biología, etc. Al primer campo corresponde, en primer lugar, por la mayor frecuencia de su cita, el ser o ente, lo existente o real, los seres o entes, en general y en concreto, la esencia o lo que es, lo en si o la mismidad; ${ }^{13}$ al campo gnoseológico pertenecen

12 Teeteto 185 a-e.

13 Fedón 65 c 3, 9; 66 a 3, c 2; República 511 c 5; 529 b-c, b 5; d 2; 530 b 8; 
la verdad y lo verdadero, el saber y la sabiduria, la ciencia, lo inteligible e invisible, ${ }^{14}$ a lo axiológico puede atribuirse, además de lo verdadero ya enumerado, lo bueno, lo bello, lo justo, lo más excelente; ${ }^{15}$ en el campo de la matemática entran la magnitud, el número y la figura; ${ }^{16}$ a la física correspondería la velocidad y la lentitud;17 a la biología, en fin, la salud y la fuerza. ${ }^{18}$

2) Tipo de conocimiento y de facultad conocitiva. También en este punto ve las cosas Platón desde diferentes ángulos, es decir, señala cierta diversidad en la facultad, los medios y las operaciones conocitivas. Como sujeto en general podemos decir que Platón se rẹfiere al alma ${ }^{19}$ y como hábitos o virtudes fundamentales a la sabiduria, al saber y a la ciencia, ${ }^{20}$ facultades son la razón, el pensamiento y la inteligencia; ${ }^{21}$ como operaciones generales se enumeran: conocer, pensar, reflexionar, considerar, observar o examinar, razonar, raciocinar, discurrir, contemplar, aprender o entender; 22 el instrumento esencial y fundamental vienen a ser naturalmente las ideas -objetos también en otros contextos- y como medios auxiliares se echa mano de hipótesis, problemas y figuras. 23

3) Incapacidad conocitiva de la sensación. Igual que en los puntos anteriores, son muchos y muy variados los aspectos o motivos que Platón aduce como negativos en la sensación en orden al conocimiento estrictamente dicho, es decir, del objeto indicado antes. Siendo muy difícil aquí una clasificación, vamos a seguir el orden de enumeración de los textos mismos, dispuestos más o menos según la importancia. Los sentidos no alcanzan la verdad, ni exactitud y evidencia, porque son incapaces o inhábiles. ${ }^{24}$ El cuerpo engaña al alma y por su medio ésta no puede examinar $u$ observar nada.25 El alma trabaja perfectamente y alcanza su objeto, cuando no es perturbada por los sentidos, cuảndo hace a un lado el cuerpo y no se le asocia ni tienie contacto

Fedón 82 e g-4; 83 b 2; 65 d-e; Repriblica $53_{2}$ a 7 , b 1; 510 d 7 ; Fedón 66 e 1-2. (E1 ordenamiento responde a la sucesión de los temas o conceptos.)

14 Fedón 65 a 9, b 2, 9, e 2; 66 a 6, b 7, d 7, e 2, 5, 6; 67 a 3, 8, b 1; Repríblica 529

b 5 , d 1-3; 532 b 2; Fedón 83 b 4; República 511 c 6 .

15 Fedón 65 d 4 -7; República 532 c 6, b 1 .

16 Fedón 65 d 12; Repríblica 529 d 3; 531 c 2-9.

17 República 529 d 2.

18 Fedon 65 d $12 \cdot 13$.

19 Fedón 65 b 9, d 1-2; 66 a 1-2, e $1 ; 67$ a $1 ; 82$ e $5 ; 83$ b 1, etc.

20 La relación tan estrecha expresada por Platón entre el ser y las ideas, como objetos, y la ciencia, la sabiduría y el saber, como disposiciones o elementos subjetivos, explica que algunas veces estos últimos sean considerados como objetos y otras como algo subjetivo. Por ej. Repriblica $5^{11}$ c 5 .

21 República 532 a 6-7, b 1; 529 d 4-5; 511 a 1, b 4, c 7; 530 c 1; Fedón 66 a 1.

${ }_{22}^{2}$ Fedón 65 b 10, 2, 5, e 2-4, 8; 66 c 5, d 7, 8, e 5 . Repriblica $5^{11}$ b $4, \mathrm{c}_{5}^{-8} ; 533$ a 8 ;

$529 \mathrm{~b} 7$; Fedón $83 \mathrm{~b}$ i.

23 Repriblica 510 b 8; 511 c 1-2; $53^{\circ}$ b 6; 510 b $7 ; 529 \mathrm{~d} 7$.

24 Fedón 65 b $1-6$.

25 Ibid. 10-11. 
con él. ${ }^{26} \mathrm{El}$ objeto del conocimiento no se alcanza con los ojos ni con ningún sentido corporal, ni mediante el cuerpo.27 El discurso o la reflexión no sólo no reciben ayuda alguna de los sentidos, sino que lo obstaculizan, perturban e imposibilitan, pues producen en el alma desorden, confusión y trastorno; por lo cual debe apartarse de ojos y oídos, y de lo corpóreo en general.28 La sensación no hace aprender o entender; la vista no conoce el ser; la razón trabaja sin los sentidos y la ciencia no tiene nada de éstos. ${ }^{29}$ En el conocimiento de lo inteligible el alma ha de proceder sin imágenes sensibles; no debe servirse en absoluto de nada sensible y no podrá contemplar los seres mismos con los sentidos. ${ }^{30} \mathrm{Si}$ en relación con determinados "objetos" la sensación posee cierta suficiencia frente al entendimiento, en relación con otros necesita de su "supervisión", porque no produce nada sano.31 Conocer mediante el cuerpo es como observar a través de una cárcel; la observación por medio de los sentidos es engañosa; el alma debe alejarse de ellos y usarlos sólo por necesidad. Lo que el alma examine por otros medios que no sean ella misma, no será verdadero, porque es sensible y visible. ${ }^{32}$

4) Trasfondo ético-práctico del rechazo de lo sensible y corpóreo. Puede sostenerse que, excepto cuando Platón hace en forma expresa un planteamiento gnoseológico del problema, la atmósfera que rodea e impregna sus afirmaciones al respecto, es de un espiritualisto y moralismo radicales. El empleo en varios casos del término sabiduria -sensatez, prudencia-33 en lugar de ciencia, entendimiento, razón, saber, etc., es un testimonio general. Pero abundan también las alusiones concretas y directas: el alma del filósofo desprecia el cuerpo y huye de él; la sabiduría es el conocimiento de lo justo, lo bello y lo bueno.34 El dolor y el placer perturban al alma, por eso debe hacer a un lado lo corpóreo, no asociársele ni tener contacto con ello. ${ }^{35}$ El conocimiento y el saber deben ser puros y limpios. ${ }^{36}$ Las preocupaciones por el cuerpo causan guerras, revoluciones y luchas, y producen desorden,

26 Ibid. $c$ 5-9.

27 lbid. d 9, 11, e 1 .

28 Id 65 e-66 a; 66 a $3-5, d$. 6 .

29 Repriblica 529 b 7, d $5 ; 532$ a 6; 529 c 1 .

30 Id. 510 b $7 \cdot 8 ; 511$ c $1,7 \cdot 8$.

a1 Id. 523 b 2-4.

32 Fedón 82 e $3 ; 83$ a $4-7$, b 2-4.

33 Aunque el término poóvnors puede tener y tiene en ocasiones un sentido de saber teórico, sin embargo, en la mayor parte de los casos significa un saber práctico, cosa que,

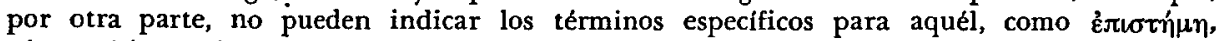

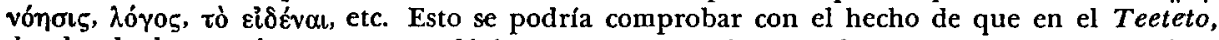
donde el planteamiento es gnoseológico, no aparece ni una sola vez aquel término, mịentras que en el Fedón, donde hay un planteamiento espiritualista -inmortalidad del alma y superioridad del espiritu-, se usa con frecuencia.

34 Fedón 65 c-d, c $4-7 ; 76 \mathrm{~d} 8$.

35 Id. 65 c 6-9.

$36 I d .66 \mathrm{~d} 8$, e 5 . 
confusión y trastorno. ${ }^{37}$ La unión con el cuerpo significa para el alma una mezcla. con algo malo.38 $\mathrm{El}$ alma debe obrar del modo más puro. El filósofo ha de apartarse limpio y puro de la insensatez o demencia del cuerpo ${ }^{39} \mathrm{y}$ alejarse de los placeres, deseos, dolores y temores, producidos por el cuerpo $\mathrm{u}$ originados en él. ${ }^{40}$

$2^{\circ}$ El carácter positivo de la doctrina platónica con respecto a la sensación aparece frecuentemente, sobre todo en el Teeteto, como puede suponerse, pero también en la República y aun en el Fedón. Tal carácter, por supuesto, debe entenderse referido no al mismo objeto con relación al cual fue presentado un carácter negativo, sino con respecto: a) a una función válida y objetiva de la sensación misma, en cuanto percepción del mundo sensible; b) a su mediación o uso en orden a la producción del conocimiento como reminiscencia; $c$ ) a su origen o procedencia, en general, de los sentidos y $d$ ) a una conformidad o coincidencia entre sensación y conocimiento.

a) La percepción del mundo sensible es, por una parte, un hecho general en los diálogos platónicos, manifiesto en todas las afirmaciones o referencias a algo sensible - colores, sonidos, cualidades del gusto, del tacto, del olfato, movimiento, figura y posición físicas, etc.- y, por otra parte, es un supuesto de otras múltiples afirmaciones y desarrollos demostrativos, que toman como punto de referencia, aun negativo, la sensación o lo sensible, como se ha dicho ya antes. Al respecto sólo me voy a referir a dos puntos. El primero es la afirmación de la existencia de los dos géneros o clases

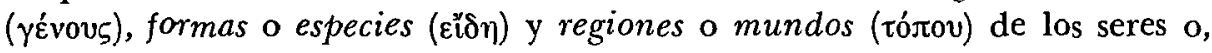
más bien, cosas: el inteligible y el visible, o también el entendido y el visto, entre los cuales habria, según los textos, unas relaciones mucho más estrechas que si el segundo (visible) fuera algo puramente irreal. ${ }^{41}$ El segundo punto es la repetidísima afirmación de todo lo sensible, en el extenso razonamiento sobre los múltiples y diversos casos de coincidencia o no coincidencia entre lo percibido por los sentidos y lo sabido o conocido por otras vías, en orden a la producción o manifestación del conocimiento. ${ }^{42}$

La percepción, captación o aprehensión misma de lo sensible o su contacto con ello, es expresada a veces con un término que corresponde en for-

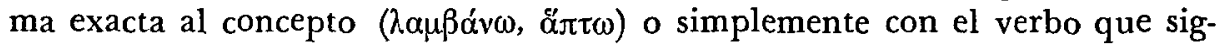
nifica una sensación determinada, como o̊ó́ (ver), ảxoúw (oír), etc. He aquí algunas breves fórmulas. A propósito de la doctrina sobre el conocimiento como reminiscencia, de acuerdo con la cual se atribuye un papel a la

37 Id. 66 c $6, \mathrm{~d} 6$.

38 Id. 66 b 5.6 .

39 Id. 65 e $6 ; 67$ a 7 .

$40 \mathrm{Id} .83 \mathrm{~b} 6 \cdot 7$.

41 República 509 d 2-4, 8. Cfr. también: $53^{2}$ b 2, c 6-8. (Cito las palabras en el caso $y$ número con que aparecen en el texto.)

42 Teeteto $191 \mathrm{c}-194 \mathrm{~d}$. 
sensación, aparece tres veces un aserto casi con idénticas palabras: ". . habiendo visto $\mathrm{u}$ oido algo o habiéndolo captado por algún otro sentido. . ; ${ }^{43}$ “...por haber visto o tocado algo o haberlo percibido con algún otro sentido...";44 "...habiendo sentido o visto u oido algo o habiéndolo captado por algún otro sentido..." $45 \mathrm{Al}$ contraponer las cosas concretas y singulares con lo en sí mismo, es decir, con las ideas relacionadas con aquéllas, dice Platón: "Las unas [cosas] decimos ciertamente que son vistas, pero no pensadas; las ideas, en cambio, decimos en verdad que son pensadas, pero no vistas... ¿Con qué parte de nosotros mismos vemos las cosas que son vistas? -Con la visión...- ¿Acaso no también... con el oido oímos las que son oidas, y con los otros sentidos todas las demás que son sentidas?" 46 En la exposición de una teoría, asimilada sin duda por Platón, acerca del carácter irracional de los elementos o primeros principios, se dice: "Así, en verdad, decimos que los elementos son irracionales $\mathrm{e}$ inconocibles, pero con todo sensibles". 47

Sin embargo, lo más importante sobre la función válida y objetiva de los sentidos es sin duda lo que Platón, aun sin emplear un término equivalente a objeto - porque el Griego aun no lo ha creado ni tal ve $e_{2}$ lo creará jamás-, ${ }^{48}$ dice explícitamente al afirmar que lo percibido por los sentidos es o existe; es decir, le atribuye la existencia o presencia entitativa, que sin duda no es la misma asignada a los objetos del conocimiento propiamente dicho y a las ideas, sino otra diversa, confusa e imprecisa, simplemente percibida como lo que aporta la sensación, pero real, puesta y dada ahí.

La afirmación más importante, a mi juicio, sobre lo que puede llamarse objetividad entitativa de la sensación, la hace Platón al discutir el problema de la posibilidad de la opinión falsa. La parte del texto que nos interesa comienza haciendo un enunciado en apariencia paradójico: "Si alguien ve algo, pero no ve nada. - ¿Y cómo? - Mas en realidad, si alguien ve algo uno, ve algo de las cosas que son. ¿O crees tú acaso que lo uno esté entre las cosas que no son? - Yo al menos no. - Por tanto, quien ve algo uno, ve algo que es. - Así parece-. Y entonces, quien oye algo, ciertamente oye algo uno y oye algo que es. - $\mathrm{Sí}$-. Y el que toca en verdad algo uno, toca también

43 Fedón 73 c 6-7. Cfr. también 74 c 13, d 9 .

44 Fedón 75 a $6-7$.

45 Id. 76 a $1-2$.

46 Repriblica 507 b g-c 4 .

47 Teeteto $202 \mathrm{~b}, 5-6$.

48 En general, cuando en las traducciones a las lenguas modernas aparece el término objeto, no responde a él directamente ninguno griego, sino que, algunas veces, se considera significado en las formas neutras de los adjetivos o participios. Otras veces, es cierto, hay

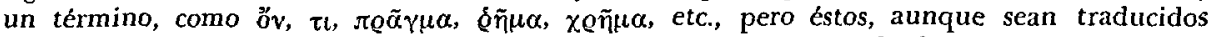
así, no significan propiamente objeto, sino ser o ente, algo, cosa, hecho, asunto, etc. Como parece más seguro, el Griego no llegó a formar un término ni a pensar un concepto para

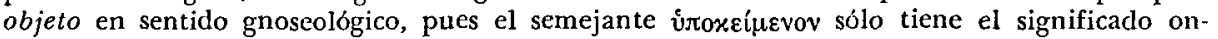
tológico de sub-stancia. En un próximo artículo para este Anuario abordaré el problema. 
algo que es, puesto que es uno. - También esto es así." 49 Sobre el texto anterior se podría objetar que, según el mismo Platón, ni lo uno ni el ser son objetos de la sensación; sin embargo, nótese bien que, en cuanto a la operación, él no habla de conocimiento, sino sólo de percepción sensible, es decir, no le atribuye el conocer a la sensación; y en cuanto al objeto, en todas las expresiones usa el indefinido algo $(\tau \iota)-\mathrm{y}$ no el determinado el o lo $(\tau \hat{)})-$, que no se refiere directamente al ser o a lo uno mismos, sino que indica una simple relación de lo dado sensiblemente con ellos.

Otra referencia expresa a la objetividad de que tratamos se encuentra en un amplio desarrollo sobre las relaciones tanto gnoseológicas como ontológicas entre las cosas particulares concretas y lo en sí o las ideas, donde Platón asigna a ambas la existencia, sin destacar en forma explícita la diferencia entre ambas, aunque sí la alude "Hay muchas cosas bellas... - dice Platón- y muchas cosas buenas, y decimos que cada una como tal existe y además las distinguimos con el lenguaje. -Lo decimos en efecto-. Y que existe también, sin duda, lo bello mismo y lo bueno mismo, y así, respecto de todas las cosas que acabamos de establecer como múltiples, hablamos de acuerdo con una sola idea de cada cosa, poniéndola como única, es decir, 'lo que es' cada una." 50 También afirma Platón que "son llamados seres" las impresiones originales o los productos primeros logrados o manifestados en el proceso de la sensación. ${ }^{51}$

De manera implícita afirma Platón tal objetividad cuando, por ejemplo, demuestra la necesaria correlación entre el sujeto y el objeto, así como la opuesta entre lo objetivo y lo subjetivo: "Y, en verdad, es necesario que yo me vuelva algo al volverme alguien que siente; pues volverse alguien que siente, pero sin sentir nada, es imposible; también es lo mismo volverse aquello para alguno, cuando se vuelve dulce o amargo o algo semejante: pues volverse dulce, pero dulce para ninguno, es imposible." ${ }^{2}$ También implícita, aunque tal vez más indirecta y lejana, se halla una referencia al valor objetivo de la sensación en el aserto platónico de que hay ciertas operaciones de los sentidos - junto con sus objetos- que no requieren, por decirlo asi, la "supervisión" del entendimiento, porque basta la apreciación misma de los sentidos - aunque en otros casos la necesitan del todo..53

b) El término más usado por Platón para expresar que las sensaciones

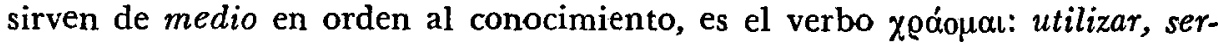

49 Teeteto 188 e $5 \cdot 189$ a 5 .

50 República 507 b 2-7. Que el texto tiene un sentido de existencia real lo comprueban otras traducciones. La de la Colección Loeb dice: We predicate 'to be' of many beautiful things and many good things saying of them severally that they are..." La de la Budé dice: "Il y a un grand nombre de belles choses, un grand nombre de bonnes choses... dont nous affirmons l'existence..."

51 Teeteto $194 \mathrm{~d}_{4}-6$.

52 Id. 160 a 8-b 3.

53 República 523 a 10-b 2. 
virse de, emplear, usar, valerse de, etc. A cuyo propósito debe notarse que, como indica el sentido mismo del término, la sensación se toma como algo diverso y externo al conocimiento mismo en cuanto tal, sin que, por otra parte, haya el menor indicio de que el objeto de la sensación pueda de algún modo convertirse en ingrediente ni siquiera material del conocimiento en sentido estricto. Además, según el contexto de las afirmaciones platónicas, el conocimiento es entendido como reminiscencia y el uso de los sentidos tiene el carácter de ocasión u oportunidad para que se despierte en el alma el recuerdo de la contemplación de las ideas. Pero adviértase que las dos precisiones anteriores no invalidan la "objetividad" especifica de la sensación en cuanto tal, es decir, su capacidad para poner en contacto al ser humano con el mundo sensible.

He aqui algunas fórmulas: “...y posteriormente, sirviéndonos de los sentidos respecto de las mismas cosas, recuperamos aquellos conocimientos que antes teníamos".54 "Por tanto, también sabes que [los geómetras] se sirven de las figuras visibles y hacen sus razonamientos con relación a ellas..." ${ }_{5}$ "De modo que el alma se ve forzada a investigar una parte de lo inteligible, sirviéndose de las imitaciones [propias del mundo sensible] como de imágenes..." 56 "Estas figuras que trazan en relieve y dibujan..., de ellas se sirven como de imágenes." 57 "... sirviéndose de las mismas imágenes representadas por las cosas de aquí abajo..." 58

La idea de instrumento es expresada también con la preposición otó, especifica para el propósito: “...por naturaleza está presente en los hombres y en los animales el sentir todas las impresiones que llegan hasta el alma a través del cuerpo".59 "... las impresiones que avanzan a través de los sentidos y que se gravan en este 'corazón' del alma..." ${ }^{60}$ Combinando las ideas de mediación y procedencia, Platón explica su punto de vista así: “... a través del amor correcto a los mancebos, asciende desde estos particulares y comienza a contemplar aquella belleza... Empezando desde estos individuos bellos, debe ascender siempre en busca de aquella belleza, sirviéndose de ellos como de escalas..." 61

c) Otro aspecto que Platón destaca en la relación entre los sentidos y el conocimiento es el de punto de partida, origen o procedencia. Pero debe advertirse también aquí, como en lo anterior, que se trata de algo externo, es decir, que los sentidos y la sensación tienen un papel de estimulo, impulso

64 Fedón 75 e $3-5$. Cfr. también 83 a 6.7: "...servirse de ellos sólo en cuanto sea necesario..."

55 Repriblica $5^{10} \mathrm{~d}_{5 \cdot 6}$.

56 Ibid. b $4-5$.

57 Ibid. e $1-3$.

$58 I d, 511$ a $6-7$.

59 Teeteto 186 b $11-\mathrm{c} 2$.

60 Id. 194 c 6-7.

61 Banquete 211 b-c. 
o excitante para que sea iniciado el proceso del conocimiento, y nada indica que sean considerados como algo interno, es decir, como base o materia sensible que por arte del entendimiento se transforme en estructura inteligible. El punto de vista de que hablamos lo expone Platón básicamente en el contexto de su doctrina sobre la reminiscencia. Tomando como ejemplo el conocimiento de la igualdad, compara las cosas que se llaman iguales, percibidas sensiblemente aquí y ahora, con la igualdad misma, conocida antes en otro mundo y re-conocida nuevamente en esta vida, y explica el nexo entre ambas

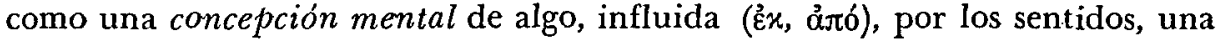
especie de "deducción" indirecta por estar implícita (દ̉vvoeiv), a partir de los datos sensibles. He aquí las fórmulas: "Si alguien, habiendo visto u oído algo o habiéndolo captado por algún otro sentido..., también pensara en otra cosa, cuyo conocimiento no es el mismo sino otro..." 62 "Siempre que, habiendo visto una cosa, a partir de esta visión pensara en otra..." 63 "Si alguien, habiendo visto algo, pensara en que esto, que yo ahora veo, tiende a ser como otra cosa de las que existen..." 64 "...habiendo visto las cosas iguales, pensamos en que todas ellas tienden a ser como lo igual... No hemos pensado en ello ni es posible pensarlo por otro medio que por haberlo visto o tocado, o por alguna otra de las sensaciones... Por efecto de los sentidos debe pensarse en que todo lo dado en las sensaciones tiende hacia aquello que es lo igual..." 65 "...habiendo sentido o visto u oído algo, o habiéndolo captado por algún otro sentido, a partir de esto piensa en algo diverso..." 66

La misma relación de procedencia se halla expresada indirectamente en un pasaje, donde el punto de partida no es la sensación misma, sino la impresión originaria, de la que justamente ella procede y de la cual proviene también la opinión. Sin embargo, lo más importante aquí es el valor conocitivo que parece atribuirse al conjunto, pero más al elemento originario. "Y respecto de la impresión presente a cada uno -dice Platón-, de donde se engendran las sensaciones y las opiniones conforme a ellas, es más difícil concebirlas como no verdaderas... y los que dicen que ellas [las impresiones] son manifiestas y las consideran como conocimientos, puede ser que digan cosas reales, y Teeteto aquí presente no ha hablado fuera de propósito al establecer como lo mismo la sensación y la ciencia." 67

d) Otras expresiones de Platón sobre el tema que nos ocupa tienen como punto de relación la coincidencia o conformidad entre conocimiento y sensación. El contexto principal es la discusión mencionada antes 68 sobre los

62 Fedón 73 c 6-8.

63 Id. $74 \mathrm{C} 14^{-\mathrm{d}} 1$.

64 Ibid. d 9-10.

65 Id. 75 a 1 -b 2.

66 Id. 76 a $1-3$.

67 Teeteto $179 \mathrm{c} 2-\mathrm{d} 1$.

68 Id. $191 \mathrm{c}-194 \mathrm{~d}$. 
múltiples casos posibles de la opinión falsa y del error, así como sus contrarios, muchos de los cuales tienen como base precisamente la convergencia o divergencia entre las imágenes y demás datos aportados por los sentidos y las ideas y demás características ideales, consideradas como productos del conocimiento. Es de advertir sobre ese amplio pasaje que, aun cuando Platón

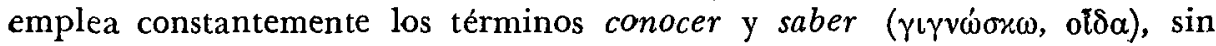
embargo, en algunos aspectos no se trata de un planteamiento riguroso y estricto, toda vez que el "conocimiento" de individuos singulares como Cebes, Teeteto, Teodoro, etc., no podría restringirse absolutamente a las características ideales o intelectivas, eliminando todo elemento sensible. Fuera de esto, la conclusión general es que de la conformidad o del acuerdo entre ambos factores surgirá el conocimiento verdadero, y al contrario, faltando aquélla, faltará éste, presentándose entonces en su lugar la opinión falsa, el error, la confusión, etc. Otra forma de plantear la conclusión es que resulta imposible juzgar falsamente, cuando la sensación concreta concuerda con lo que se sabe.69 También puede decirse que de todo lo expuesto ahi se desprende que los dos elementos son considerados por Platón necesarios para el conocimiento siempre y cuando, por supuesto, se trate del objeto por conocer ahí y del mismo planteamiento, es decir, un objeto susceptible de afectar los órganos de los sentidos y de dejar huellas en la "parte" sensitiva o instrumento sensible del alma. ${ }^{70} \mathrm{He}$ aquí algunas fórmulas más directas: “...Cuando conociendo a ambos, al uno, además de conocerlo, lo percibo sensiblemente, al otro en cambio no, y el conocimiento del primero no lo tengo de acuerdo con la sensación..." 71 "... conociendo al uno y percibiéndolo sensiblemente, y teniendo el conocimiento de acuerdo con la sensación del mismo, jamás juzgará que él es algún otro de los que conoce y percibe sensiblemente, de quien también tiene, una vez más, conocimiento conforme con la sensación". ${ }^{2}$ Otro caso de opinión errónea es el de aquel que, "...conociendo a ambos y viendo a ambos o teniendo de ellos alguna otra sensación, posee las señales de ambos no conformes en cada uno con la sensación propia..." 73 "Y cuando, además, a una de las señales se añade la sensación, y a otra en cambio no, y aquella, a la que falta la sensación, se aplica a la que está presente, yerra así en forma total el pensamiento... Pero respecto de aquellas cosas que sabemos y también sentimos, en ellas precisamente da vueltas y gira la opinión que resulta falsa y verdadera: en efecto, si acopla de frente y en forma directa los modelos y las impresiones, será verdadera;

69 Id. $192 \mathrm{~b} 2-5$.

70 Id. $192 \mathrm{~d}$ y 193 a.

71 Id. $193 \mathrm{~d} 5.7$. Con ambos Platón se refiere a Teeteto y a Teodoro, de quienes se sirve en la ejempliticación.

72 lbid. d 10-e 4.

73 Ibid. 193 e v-194 a 2. 
si de flanco y oblicuamente, será falsa." 74 “... . además, no desvían de las sen, saciones las señales, sino que opinan con verdad. Pues siendo ellas claras y hallándose en un lugar espacioso, rápidamente las distribuyen sobre las impresiones propias de cada una, las cuales en verdad se llaman seres..."

Al aspecto estudiado en este párrafo puede reducirse lo que Platón expresa sobre las relaciones entre lo captado por los sentidos y lo conocido en sí y por sí mismo, en el contexto de uno de los argumentos para demostrar la inmortalidad del alma: “. . . si en verdad existe... lo bello y lo bueno y toda esencia semejante, y si referimos a ésta todo lo procedente de las sensaciones... y si asemejamos esto a aquélla..."76

\section{V}

El resultado del contacto directo e indirecto con los textos y las doctrinas platónicas -estudiados más bien en conjunto, pero tal vez no analizados en detalle y a fondo- puede formularse, en su punto capital, diciendo que el llamado idealismo platónico tiene, si no como complemento gnoseológico estricto, sí como elemento adyacente, o tal vez subyacente, un realismo. Aquel idealismo es ideal - para no decir trascendental - por fundarse o, más bien, por estar constituido por las ideas, independientemente de que a éstas se atribuya la "verdadera" realidad y existencia; pues es evidente, por una parte, que además de su valor o "entidad" ontológica, las ideas tienen una función gnoseológica $y$, por otra, lo aportado por la sensación posee también una realidad y existencia, así sea inferior, inestable, evanescente, inasible. El realismo que se puede afirmar fundado en este tipo de realidad es legítimo e irrechazable, si por real entendemos lo presente, lo dado y puesto ahi, lo irreductible a la nada, es decir, la pura nota existencial, fuera de toda característica o determinación, tanto sensible como inteligible, que gnoseológicamente vendría después. Este realismo equivaldría, básicamente, al empírico kantiano, por tener su origen en la sensibilidad. El realismo platónico de las ideas, a su vez, equivaldría al idealismo trascendental de Kant, ya que la realidad que lo funda es la del mundo eidético, convertido en ontológico - también en Kant podría hablarse de un realismo trascendental, si por verdadera realidad entendiéramos sólo la constituida por las categorías del entendimiento.

En lo que toca al alcance y objeto de los sentidos, la actitud negativa de Platón se refiere únicamente a dos cosas: una, a su incapacidad específica para conocer el ser y la verdad, así como las ideas y las realidades mismas; otra, a la no aportación de ellos para ese conocimiento, en el sentido de constituirse en ingrediente específico suyo de cualquier naturaleza. Tal actitud no se refiere, a su vez, a dos cosas: una, a la relación de aquéllos, como instru-

74 Ibid. 194 a 6-8, b $2-6$.

75 Ibid. d $3^{-6}$.

76 Fedón $76 \mathrm{~d} 7$-e 2. 
mento y medio de contacto, con el mundo sensible o físico, respecto del cual no hay el menor argumento para considerarlo negado, no ya en su existencia y presencia, pero tampoco en su uso y disfrute, sin que signifique nada en contra que se lo considere no como ser sino como devenir, no como verdad sino como apariencia; otra, a la posibilidad de constituirse en elemento específico de un tipo diverso de "conocimiento", afirmado en forma implícita, al que Platón parece llamar opinión y que se ocuparía de relacionar, en lo posible, lo percibido por la sensación - movimiento, color y sonido en astronomía, física y música - con los conceptos ideales, sea genéricos, como unidad, igualdad, diversidad, relación, número, etc., sea los especificos, por ejemplo, geométricos y matemáticos, propios de esas ciencias.

Por otra parte, parece evidente que Platón en realidad no se planteó en forma radical y total el problema del influjo de los sentidos en el conocimiento, de tal modo que se pudiera eliminar con carácter absoluto la presencia de la sensación en el conocimiento. En lo fundamental sólo se propuso retirar a la sensación la categoría de conocimiento en sentido estricto. Y que él mismo no pensó en la eliminación absoluta, lo demuestran las varias funciones que asigna a la sensación en orden al conocimiento, aun cuando sean externas y ocasionales. A mi juicio, los planteamientos de Platón vienen a ser ensayos primeros y valiosísimos para deslindar las funciones y los objetos de los dos factores o instrumentos de que dispone el ser humano para su contacto con el mundo en que vive y al que crea, visible en un aspecto e inteligible en otro.

En cuanto al rechazo eventual de todo lo relativo al cuerpo y a lo sensible, debe decirse que Platón enfoca el problema en algunos lugares desde un ángulo ético evidente, con el propósito de elevar al hombre a un plano espiritualista, lejos de los goces y placeres sensibles, asi como de la mezcla y corrupción de lo corpóreo. Pero este enfoque no puede considerarse como opuesto o contradictorio del gnoseológico, ya que es fácil advertir, por una parte, que lo dicho por Platón en favor y en contra de los sentidos en el plano gnoseológico no puede tomarse como argumento en el ético, y por atra, que los argumentos éticos no pueden refutar en forma directa y estricta las tesis gnoseológicas.

En resumen, la gnoseología platónica, que se halla en un primer estadio de acercamiento al problema, atribuye a la sensación lo que toda filosofía sana y recta debe atribuirle y le retira lo que debe quitarle, estableciendo así, por primera vez en la historia del pensamiento, las bases para una delimitación decisiva y fundamental entre las dos potencias conocitivas del ser humano, correspondientes a los dos modos de su ser.

INSTITUTO DE INVESTIGACIONES FILOSÓFICAS

Bernabé Navarro

Universidad Nacional Autónoma de México 